\title{
Synthesis and Characterization of a Semiaromatic Polyamide Comprising Benzofurobenzofuran Repeating Units
}

\author{
Julien Cretenoud, ${ }^{1}$ Bilal Özen, ${ }^{1}$ Thomas Schmaltz, ${ }^{1}$ Daniel Görl, ${ }^{1}$ Alberto Fabrizio, ${ }^{2}$
}

Clémence Corminboeuf, ${ }^{2}$ Farzaneh Fadaei Tirani, ${ }^{3}$ Rosario Scopelliti, ${ }^{3}$ Holger Frauenrath ${ }^{1, *}$

${ }^{1}$ Ecole Polytechnique Fédérale de Lausanne (EPFL)

Institute of Materials

Laboratory of Macromolecular and Organic Materials

EPFL-STI-IMX-LMOM

MXG 037, Station 12

1015 Lausanne, Switzerland

holger.frauenrath@epfl.ch

${ }^{2}$ Ecole Polytechnique Fédérale de Lausanne (EPFL)

Institute of Chemical Science and Engineering

Computational Molecular Design Laboratory

${ }^{3}$ Ecole Polytechnique Fédérale de Lausanne (EPFL)

Institute of Chemical Science and Engineering 


\section{Abstract}

Semiaromatic polyamides are attractive engineering polymers owing to their outstanding thermomechanical properties. To expand the scope of semiaromatic polyamides by additional optoelectronic features, one may consider to incorporate extended $\pi$-conjugated systems based on fused heterocycles into the polymer backbone. Here, we report on the synthesis of a benzofurobenzofuran monomer along with its structural characterization and an investigation of its packing behavior. A corresponding semiaromatic polyamide was prepared by solution-phase polycondensation under Yamazaki-Higashi conditions which was characterized and investigated with respect to its chemical and supramolecular structure, as well as its thermal and optoelectronic properties. Molecular computations suggested that the unfavorable HOMO and LUMO levels of the employed benzofurobenzofuran core impeded efficient charge transport in these materials. While our work thus paves the way towards polyamide-based semiconductors, the latter will require more sophisticated $\pi$-conjugated systems. 


\section{Introduction}

Semiaromatic polyamides are attractive engineering polymers as they combine the strength and stiffness brought by the rigid aromatic repeating units with a higher ductility due to the incorporation of flexible aliphatic repeating units. ${ }^{1-4}$ For the same reason, they are also significantly better processable than aromatic polyamides such as Kevlar or Nomex that cannot be processed by melt extrusion or injection molding.5,6 The use of kinked aromatic repeating units decreases the crystallinity of the polyamide, which, in turn, results in further facilitated and enhanced processability.7,8 Moreover, kinked and extended $\pi$-conjugated building blocks into the polyamide backbone can be employed to introduce optical or electronic properties without negatively impacting the processing of the material.

One such building block is benzofurobenzofuran (BFBF), which we chose as a model compound for our investigations because of its similarity to benzothienobenzothiophene derivatives. The $C_{2 \mathrm{~h}}$-symmetric benzothieno[3,2-b]benzothiophene (BTBT) derivatives have shown excellent charge transport properties in thin film transistor devices. ${ }^{9-12}$ Significant efforts have been devoted to investigating the correlation between the chemical structure, morphology, and electronic properties of BTBT-based materials, ${ }^{13-15}$ including the incorporation of BTBT units into polymer semiconductors that exhibited high charge carrier mobilites. ${ }^{16}$ However, polyamides comprising repeating units based on either BTBT or its oxygen-analogue BFBF have not previously been reported. Different from BTBT derivatives, the benzofurobenzofuran core is readily accessible in larger quantities via its dihydro-derivatives that, in turn, can be straightforwardly synthesized in an acid-catalyzed condensation reaction of glyoxal derivatives with a variety of $p$-substituted phenols.17,18 Contrary to initial expectations, the regioselectivity of this reaction was reported to not favor the formation of the 2,7-disubstituted dihydrobenzofuro[3,2- $b]$ benzofurans $\quad\left(C_{2}\right.$-symmetric $)$ but instead the 2,9-disubstituted dihydrobenzofuro[2,3-b]benzofurans $\left(C_{\mathrm{s}}\right.$-symmetric) (Scheme 1). ${ }^{19}$ Since the condensation reactions are fast and can easily be scaled up to the multi-gram scale, BFBF units are interesting candidates as aromatic building blocks in semiaromatic polyamides. Additionally, they may provide interesting optical and electronic properties, as recently observed in similar benzofurane-containing molecules, especially in terms of carrier mobility. ${ }^{20,21}$

The preparation of polyamides incorporating BFBF-units requires the synthesis of the corresponding dihydrobenzofurobenzofuran 2,9-dicarboxylic acid derivatives and their complete aromatization by 
dehydrogenation. According to previously described procedures, the aromatic benzofurobenzofuran dicarboxylic acid can, for instance, be synthesized in two steps starting from $p$-cresol.22-25 Banashemi et al. reported the synthesis of the cis-5a,10b-dihydro-2,9-dimethylbenzofuro[2,3- $b$ ]benzofuran from glyoxal and $p$-cresol, followed by an oxidation reaction with potassium permanganate. They concluded from ambiguous analytical data that this reaction simultaneous dehydrogenated the BFBF core and oxidized the methyl groups to carboxylic acid moieties.

Here, we demonstrate that the reported synthesis does not result in complete aromatization to the desired benzofurobenzofuran molecule but that a water adduct is obtained instead. We show that the targeted $C_{2 \mathrm{v}}$-symmetric benzofurobenzofuran dicarboxylic acid can successfully be prepared in three additional steps starting from this hydrated intermediate. Moreover, we demonstrate that benzofurobenzofuran derivatives are compatible with typical activation conditions for the polycondensation with diamines. We have thus prepared the corresponding semiaromatic polyamides by polycondensation of benzofurobenzofuran dicarboxylic acid with an aliphatic diamine and report its thermal as well as optoelectronic properties.

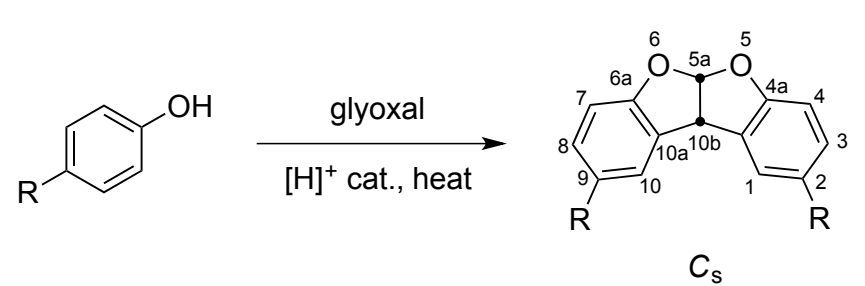

2,9-disubstituted dihydrobenzofuro[2,3-b]benzofuran

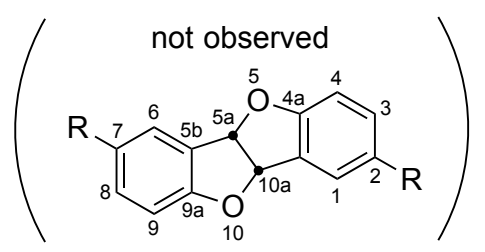

$\mathrm{C}_{2}$

2,7-disubstituted dihydrobenzofuro[3,2-b]benzofuran

Scheme 1. The acid-catalyzed reaction condensation of glyoxal derivatives with two equivalents of $p$-substituted phenols yields the $C_{\mathrm{s}}$-symmetric 2,9-disubstituted dihydrobenzofuro[2,3-b]benzofuran and not the $C_{2}$-symmetric 2,7-disubstituted dihydrobenzofuro[3,2-b]benzofuran. ${ }^{19}$

\section{Experimental}

\section{Materials and Instrumentation}

Materials. All materials and solvents for reactions were purchased from commercial suppliers and used without further purification. Chromatography solvents were purchased as reagent grade and distilled once prior to use. The progress of reactions was monitored by thin-layer chromatography (TLC) on Merck TLC plates (Silica gel $60 \mathrm{~F}_{254}$ ) using DCM/MeOH (9:1 or 19:1) as the eluent. UV light (254 nm) was used for detection of compounds on the TLC plates. 
Spectroscopy and Mass Spectrometry. NMR spectroscopy was carried out at $298 \mathrm{~K}$ on a Bruker Avance III 400 spectrometer at frequencies of $400 \mathrm{MHz}$ and $100 \mathrm{MHz}$, respectively, for ${ }^{1} \mathrm{H}$ and ${ }^{13} \mathrm{C}$ nuclei. The spectra were calibrated to the residual solvent peaks of DMSO- $d^{6}\left(2.50 \mathrm{ppm}{ }^{1} \mathrm{H}\right.$ NMR; $39.52 \mathrm{ppm}{ }^{13} \mathrm{C}$ $\mathrm{NMR}$ ) or $\mathrm{CDCl}_{3}\left(7.26 \mathrm{ppm}{ }^{1} \mathrm{H}\right.$ NMR; $\left.77.16 \mathrm{ppm}{ }^{13} \mathrm{C} \mathrm{NMR}\right) .{ }^{1} \mathrm{H}-1 \mathrm{H}$ correlation spectroscopy (COSY) and ${ }^{1} \mathrm{H}-$ ${ }^{13} \mathrm{C}$ heteronuclear single-quantum correlation spectroscopy (HSQC) were recorded using the same instrument. The ${ }^{1} \mathrm{H}$ NMR spectrum of the polyamide was recorded in non-deuterated 1,1,1,3,3,3hexafluoropropan-2-ol with acetone- $d^{6}$ as the internal standard (2.05 ppm in ${ }^{1} \mathrm{H}$ NMR). Infrared (IR) spectra were recorded on a JASCO FT/IR 6300 spectrometer equipped with an ATR crystal. Solutionphase UV-vis spectra in 1,1,1,3,3,3-hexafluoropropane-2-ol (HFIP) using Hellma quartz cuvettes (1 mm path length), and UV-Vis spectra of thin films processed by drop-casting were recorded on a Jasco V-670 spectrometer. Stock solutions were prepared by letting 1.6-1.8 mg of material slowly dissolve at room temperature in 20 mL HFIP. High-resolution mass spectrometry was carried out on either a Waters QToF Ultima for ESI, on a Bruker AutoFlex Speed for MALDI-ToF or on a Waters QTOF Xevo G2-S for APPI. X-ray Structure Analysis. Single-crystal X-ray diffraction of compounds $\mathbf{6}$ and $\mathbf{8}$ was performed at low temperature [140(2) K] and [100(2) K], respectively, using Cu Ka radiation on a RigakuSuperNova dual system equipped with an Atlas CCD detector. The datasets were reduced and corrected for absorption with CrysAlisPro. ${ }^{26}$ The solution and refinement for the structures were performed by SHELXT27 and SHELXL-2016 (release 6), ${ }^{28}$ respectively. The crystal structures were refined using full-matrix leastsquares based on $F^{2}$ with all non-hydrogen atoms anisotropically refined. The hydrogen atoms were found in the difference map and their positions were refined in the case of $\mathbf{8}$. In the crystal structure of 6, the hydrogen atoms attached to the carbon atoms were placed in calculated positions by means of the "riding" model. The structure of $\mathbf{6}$ includes three ethanol solvent molecules in the asymmetric unit which one is disordered over two positions. The atoms of each orientation were identified in the difference Fourier map. The major and minor parts were refined anisotropically, but distance and similarity restraints (DFIX and SIMU) had to be applied for a convergent least-square refinement, yielding site occupancy ratios of $0.736(5) / 0.264(5)$.

Computations. All computations were performed using the Turbomole 7.1 package. ${ }^{29}$ Ground state geometries were optimized at the $\mathrm{PBE}^{30}$ level using the def2-SVP11,32 basis set. Excitation energies were computed both at the ADC(2)33,34 and at the TD-PBE035 level within the Tamm-Dancoff approximation. 
In the $\mathrm{ADC}(2)$ computations, the resolution of identity and the frozen core approximation were employed. The density differences were visualized with the Avogadro ${ }^{36}$ software package.

Gel Permeation Chromatography (GPC). The number and weight average molecular weights, $M_{\mathrm{n}}$ and $M_{\mathrm{w}}$, as well as the dispersity index, $\oplus$, of the polyamide was determined using an Agilent 1260 Infinity GPC/SEC system with a refractive index detector and a total column length of $650 \mathrm{~mm}$ (PSS PFG, $100 \AA$ ). 1,1,1,3,3,3-hexafluoropropane-2-ol (HFIP) was used as the eluent at a flow rate of $1 \mathrm{~mL} / \mathrm{min}$ and temperature of $25{ }^{\circ} \mathrm{C}$. Six poly(methyl methacrylate) (PMMA) standards with molar masses between 2'000 and 44'000 g/mol and $\oslash \leq 1.1$ were used for calibration. The polyamide and PMMA standards were all dissolved in neat HFIP $(c=2 \mathrm{mg} / \mathrm{mL})$.

Thermal Characterization. Thermogravimetric analyses (TGA) were conducted on a Perkin Elmer TGA 4000. Samples (5-10 mg) were dried in high vacuum at $80^{\circ} \mathrm{C}$ for $24 \mathrm{~h}$ and then heated from $30^{\circ} \mathrm{C}$ to $950^{\circ} \mathrm{C}$ at a scanning rate of $10^{\circ} \mathrm{C} / \mathrm{min}$ in a flow of nitrogen or air $(20 \mathrm{~mL} / \mathrm{min})$. Differential scanning calorimetry (DSC) measurements were performed on a TA Instruments Q100 calorimeter at a scanning rate of $10^{\circ} \mathrm{C} / \mathrm{min}$ in a flow of nitrogen $(50 \mathrm{~mL} / \mathrm{min})$. Samples of about $5 \mathrm{mg}$ were first heated to $220^{\circ} \mathrm{C}$ and then cooled to $0^{\circ} \mathrm{C}$ at $10^{\circ} \mathrm{C} / \mathrm{min}$ in order to erase the effect of their prior thermal history. The data given for the thermal transitions were obtained from the second heating scan between 0 and $370^{\circ} \mathrm{C} . T_{\mathrm{g}}$ was defined as the half-height of the heat capacity step associated with the glass transition.

Wide-Angle X-ray Scattering. Wide-angle X-ray scattering (WAXS) pattern of PA6B powder was obtained in reflection mode (Bruker D8 Discover powder diffractometer, $\mathrm{Cu} K \alpha, \lambda=1.54 \AA$ ) from the surface of the powder.

Thin Film Transistors. Thin film transistors were fabricated in top- as well as bottom-contact configuration. In all cases, silicon wafers with a $100 \mathrm{~nm}$ thermal $\mathrm{SiO}_{2}$ layer served as substrates. The silicon was used as common gate electrode, and the $\mathrm{SiO}_{2}$ as the dielectric. Bottom source/drain electrodes were lithographically patterned, top contacts were patterned via shadow masks. In all cases, gold was used as the electrode material. The BFBF polyamide and the model compounds $\mathbf{7}$ and $\mathbf{8}$ were spin-coated or drop-cast onto the substrates from HFIP (8, PA6B) or toluene (7) solution. The devices were electronically characterized in the inert atmosphere of a glovebox with a Keithley 4200 parameter analyzer. 
Synthetic Procedures and Analytical Data

cis-5a,10b-dihydro-2,9-dimethylbenzofuro[2,3-b]benzofuran (1). The synthesis of compound 1 was adapted from literature. ${ }^{22} \mathrm{~A}$ three-neck round-bottom flask was fitted with a reflux condenser and a dropping funnel. Glyoxal sodium bisulfite (28.4 g, $0.100 \mathrm{~mol})$ and $p$-cresol (21.6 g, $20.9 \mathrm{~mL}, 0.200 \mathrm{~mol})$ were suspended in a mixture of $\mathrm{H}_{2} \mathrm{O}(320 \mathrm{~mL})$ and acetic acid $(150 \mathrm{~mL})$. The mixture was then heated at $85^{\circ} \mathrm{C}$ and concentrated sulfuric acid $(96 \%, 140 \mathrm{~mL})$ was then slowly added dropwise to the obtained solution over $3 \mathrm{~h}$ under strong stirring. After cooling to room temperature, the obtained green precipitate was filtered off and washed with water and EtOH until the product turned white. Drying the product in vacuum afforded pure $1\left(8.42 \mathrm{~g}, 35 \%\right.$ yield). ${ }^{1} \mathrm{H}$ NMR (400 MHz, DMSO-d 6 ): $\delta=7.35$ (d, $J=1.9$ $\mathrm{Hz}, 2 \mathrm{H}), 6.99-6.91(\mathrm{~m}, 3 \mathrm{H}), 6.76(\mathrm{~d}, J=8.1 \mathrm{~Hz}, 2 \mathrm{H}), 5.07(\mathrm{~d}, J=6.7 \mathrm{~Hz}, 1 \mathrm{H}), 2.24(\mathrm{~s}, 6 \mathrm{H}) \mathrm{ppm} .{ }^{13} \mathrm{C}$ NMR (101 MHz, DMSO-d $\left.{ }^{6}\right): \delta=155.14,130.64,128.90,127.65,124.85,112.55,109.05,49.33,20.38$ ppm. HRMS (ESI): calcd for $\mathrm{C}_{16} \mathrm{H}_{15} \mathrm{O}_{2}([\mathrm{M}+\mathrm{H}]+)$ ): 239.1072; found: 239.1079 .

Benzofuro[2,3-b]benzofuran-2,9-dicarboxylic acid (2). The benzofurobenzofuran diester 5 (0.68 g, $2.1 \mathrm{mmol})$ was suspended in a THF/water solution $(100 \mathrm{~mL}, 4: 1)$ before addition of LiOH $(0.41 \mathrm{~g}$, $17 \mathrm{mmol}, 8$ equiv.). The mixture was then heated to reflux for $3 \mathrm{~h}$. After cooling the solution to room temperature, the THF was removed under reduced pressure, and the residue was diluted with more water $(80 \mathrm{~mL})$. The aqueous solution was acidified to $\mathrm{pH} 1$ with $\mathrm{HCl}(6 \mathrm{M})$, and the resulting yellow precipitate was filtered and washed with water as well as $\mathrm{Et}_{2} \mathrm{O}$ until the complete disappearance of the yellow color. After drying in vacuo, the dicarboxylic acid $\mathbf{2}$ was obtained as a white powder and used without further purification (0.55 g, 89\% yield). ${ }^{1} \mathrm{H}$ NMR (400 MHz, DMSO-d6): $\delta=13.05(\mathrm{~s}, 2 \mathrm{H}), 8.80$ (s, 2H), $7.99(\mathrm{~d}, J=8.6 \mathrm{~Hz}, 2 \mathrm{H}), 7.88(\mathrm{~d}, J=8.7 \mathrm{~Hz}, 2 \mathrm{H})$ ppm. ${ }^{13} \mathrm{C}$ NMR $\left.(101 \mathrm{MHz}, \text { DMSO-d })^{6}\right): \delta=167.19$, 166.39, 157.31, 127.54, 125.17, 122.68, 122.13, 112.58, 96.83 ppm. HRMS (MALDI): calcd for $\mathrm{C}_{16} \mathrm{H}_{7} \mathrm{O}_{6}$ ([M $\left.\mathrm{M}_{2}-\mathrm{H}\right]$ ) ): 591.0564; found: 591.0556.

cis-5a-hydro-10b-hydroxybenzofuro[2,3-b]benzofuran-2,9-dicarboxylic acid (3). Compound 1 $(8.40 \mathrm{~g}, 35.3 \mathrm{mmol})$ was suspended in a pyridine/water mixture $(340 \mathrm{~mL}, 10: 7)$ in a three-neck roundbottom flask equipped with a reflux condenser. The suspension was heated to $90^{\circ} \mathrm{C}$, and then $\mathrm{KMnO}_{4}$ (66.8 g, $0.424 \mathrm{~mol}, 12$ equiv.) was added carefully and portionwise over $30 \mathrm{~min}$. The temperature was then raised to $120^{\circ} \mathrm{C}$, and reflux was continued for $5 \mathrm{~h}$. After cooling, the formed $\mathrm{MnO}_{2}$ was filtered off, and the filtrate was acidified to $\mathrm{pH} 1-2$ with concentrated $\mathrm{HCl}(37 \%, 400 \mathrm{ml})$. The precipitated crude 
product was filtered off, washed with water, and recrystallized from EtOH/ $\mathrm{H}_{2} \mathrm{O}(300 \mathrm{~mL}, 1: 1)$ to afford pure 3 (8.75 g, 86\% yield) as white crystals. ${ }^{1} \mathrm{H}$ NMR (400 MHz, DMSO- $\left.d^{6}\right): \delta=12.92(\mathrm{~s}, 2 \mathrm{H}), 8.18(\mathrm{~d}, J=$ $1.9 \mathrm{~Hz}, 2 \mathrm{H}), 7.88(\mathrm{dd}, J=8.5,1.9 \mathrm{~Hz}, 2 \mathrm{H}), 7.25(\mathrm{~s}, 1 \mathrm{H}), 7.08(\mathrm{~d}, J=8.4 \mathrm{~Hz}, 2 \mathrm{H}), 6.77(\mathrm{~s}, 1 \mathrm{H}) \mathrm{ppm} .{ }^{13} \mathrm{C}$ NMR (101 MHz, DMSO-d ${ }^{6}$ ): $\delta=166.47,161.61,132.32,130.13,125.47$ (2 C), 118.29, 110.58, 86.36 ppm. HRMS (MALDI): calcd for $\mathrm{C}_{32} \mathrm{H}_{19} \mathrm{O}_{14}\left(\left[\mathrm{M}_{2}-\mathrm{H}\right]-\right)$ ): 627.0775; found: 627.0803 .

Dimethyl cis-5a-hydro-10b-hydroxybenzofuro[2,3-b]benzofuran-2,9-dicarboxylate (4). The dicarboxylic acid 3 (2.25 g, $7.16 \mathrm{mmol}$ ) was dissolved in $\mathrm{HCl} / \mathrm{MeOH}(80 \mathrm{~mL}, 1.25 \mathrm{M})$ and heated to reflux overnight. Evaporation of the solvent yielded a crude material that was purified by column chromatography (silica gel, DCM/MeOH 9:1) to obtain pure diester 4 as a white powder $(2.21 \mathrm{~g}, 90 \%$ yield). ${ }^{1} \mathrm{H}$ NMR (400 MHz, DMSO- $\left.d^{6}\right): \delta=8.23(\mathrm{~d}, J=1.9 \mathrm{~Hz}, 2 \mathrm{H}), 7.90(\mathrm{dd}, J=8.5,1.9 \mathrm{~Hz}, 2 \mathrm{H}), 7.28(\mathrm{~s}$, 1H), $7.11(\mathrm{~d}, J=8.5 \mathrm{~Hz}, 2 \mathrm{H}), 6.80(\mathrm{~s}, 1 \mathrm{H}), 3.84(\mathrm{~s}, 6 \mathrm{H})$ ppm. ${ }^{13} \mathrm{C}$ NMR $\left(101 \mathrm{MHz}, \mathrm{DMSO}-\mathrm{d}^{6}\right): \delta=165.44$, 161.86, 132.33, 130.25, 125.43, 124.36, 118.33, 110.87, 86.36, 52.12 ppm. HRMS (APPI): calcd for $\mathrm{C}_{18} \mathrm{H}_{14} \mathrm{O}_{7} \mathrm{Na}\left([\mathrm{M}+\mathrm{Na}]^{+}\right): 365.0638$; found: 365.0632. $\mathrm{R}_{\mathrm{f}} 0.90$ (DCM/MeOH 9:1).

Dimethyl benzofuro[2,3-b]benzofuran-2,9-dicarboxylate (5). A flame-dried $100 \mathrm{~mL}$ Schlenk flask was purged with argon and charged with diester 4 (1.27 g, $3.62 \mathrm{mmol})$ as well as anhydrous pyridine (20 mL). The resulting solution was cooled to $0^{\circ} \mathrm{C}$ using an ice bath, and then $\mathrm{POCl}_{3}(1.4 \mathrm{~mL}, 4$ equiv.) was added dropwise under continued stirring. The ice bath was removed and stirring continued at room temperature for $2 \mathrm{~h}$ to afford a precipitate. The reaction mixture was transferred into a separatory funnel and diluted with cold water $(100 \mathrm{~mL})$. The aqueous phase was extracted using DCM $(3 \times 25 \mathrm{~mL})$. The combined organic phases were dried with $\mathrm{MgSO}_{4}$, and the solvent was evaporated under reduced pressure. After drying in vacuum, the crude benzofurobenzofuran diester $\mathbf{5}$ was recrystallized from hot toluene to yield small white needles $\left(1.00 \mathrm{~g}\right.$, 83\% yield). ${ }^{1} \mathrm{H}$ NMR $\left(400 \mathrm{MHz}\right.$, DMSO- $\left.d^{6}\right): \delta=8.83(\mathrm{~d}, J=$ $1.8 \mathrm{~Hz}, 2 \mathrm{H}), 7.99$ (dd, $J=8.7,1.9 \mathrm{~Hz}, 2 \mathrm{H}), 7.90(\mathrm{~d}, J=8.7 \mathrm{~Hz}, 2 \mathrm{H}), 3.93(\mathrm{~s}, 6 \mathrm{H}) \mathrm{ppm} .{ }^{13} \mathrm{C}$ NMR $(101 \mathrm{MHz}$, DMSO- $d^{6}$ ): $\delta=166.49,166.12,157.42,126.36,125.05,122.74,122.11,112.80,96.81,52.28$ ppm. HRMS (ESI): calcd for $\mathrm{C}_{36} \mathrm{H}_{25} \mathrm{O}_{12}\left(\left[\mathrm{M}_{2}+\mathrm{H}\right]^{+}\right)$: 649.1342; found: 649.1341 .

$N, N$ '-dipropyl cis-5a-hydro-10b-hydroxybenzofuro[2,3-b]benzofuran-2,9-dicarboxamide (6). Dicarboxylic acid 3 (0.51 g, $1.72 \mathrm{mmol})$ was suspended in $10 \mathrm{~mL}$ DMF before 1-ethyl-3-(3dimethylaminopropyl)carbodiimide (EDCI) (0.73 g, 3.79 mmol, 2.2 equiv.) and 1-hydroxybenzotriazole hydrate (HOBt) (0.58 g, $3.79 \mathrm{mmol}, 2.2$ equiv.) were added. The mixture was stirred at room 
temperature for $30 \mathrm{~min}$ until a clear solution was obtained. Eventually, propylamine $(0.23 \mathrm{~g}, 3.79 \mathrm{mmol}$, 2.2 equiv.) and $\mathrm{N}, \mathrm{N}$-diisopropylethylamine (DIPEA) (0.93 g, $7.22 \mathrm{mmol}, 4.2$ equiv.) were added, and the solution was stirred at room temperature overnight. The clear solution was then poured into $150 \mathrm{~mL}$ water and the resulting white precipitate was filtered off, washed with water, and dried in vacuum. Transparent, needle-like single crystals of dicarboxamide 6 (272 mg, 42\% yield) suitable for X-ray analysis were obtained by recrystallization from a hot EtOH solution and slow evaporation of the solvent. ${ }^{1} \mathrm{H}$ NMR (400 MHz, DMSO- $\left.d^{6}\right): \delta=8.42(\mathrm{t}, J=5.8 \mathrm{~Hz}, 2 \mathrm{H}), 8.16(\mathrm{~d}, 2 \mathrm{H}, J=1.8 \mathrm{~Hz}), 7.79(\mathrm{dd}, J=8.5$, $1.9 \mathrm{~Hz}, 2 \mathrm{H}), 7.09$ (s, 1H), 7.02 (d, $J=8.5 \mathrm{~Hz}, 2 \mathrm{H}), 6.68$ (s, 1H), 3.21 (dp, $J=19.5,6.3 \mathrm{~Hz}, 4 \mathrm{H}), 1.52(\mathrm{~h}, J=$ $7.3 \mathrm{~Hz}, 4 \mathrm{H}), 0.88(\mathrm{t}, J=7.4 \mathrm{~Hz}, 6 \mathrm{H}) \mathrm{ppm} .{ }^{13} \mathrm{C}$ NMR (101 MHz, DMSO-d 6 ): $\delta=165.18,160.21,129.77$, 129.64, 129.37, 123.68, 118.18, 109.88, 86.91, 41.01, 22.44, 11.48 ppm. HRMS (ESI): calcd for $\mathrm{C}_{22} \mathrm{H}_{25} \mathrm{~N}_{2} \mathrm{O}_{5}\left([\mathrm{M}+\mathrm{H}]^{+}\right)$: 396.1764; found: 396.1768. $\mathrm{R}_{\mathrm{f}}: 0.35$ (DCM/MeOH 19:1).

$\boldsymbol{N}, \boldsymbol{N}$ '-dipropyl benzofuro[2,3-b]benzofuran-2,9-dicarboxamide (7). Dicarboxylic acid 2 (0.99 g, 3.34 mmol) was suspended in $28 \mathrm{~mL}$ DMF before EDCI (1.41 g, $7.35 \mathrm{mmol}, 2.2$ equiv.) and HOBt (1.13 g, 7.35 mmol, 2.2 equiv.) were added. The mixture was stirred at room temperature for 20 min until a clear solution was obtained. Eventually, propylamine ( $0.43 \mathrm{~g}, 7.35 \mathrm{mmol}, 2.2$ equiv.) and DIPEA (1.81 g, 14.0 mmol, 4.2 equiv.) were added, and the solution was stirred at room temperature overnight. The clear solution was then poured into $350 \mathrm{~mL}$ water and the resulting precipitate was filtered off, washed with water, and dried in vacuum. The crude product was purified by column chromatography (silica gel, DCM/MeOH 19:1) to obtain pure dicarboxamide 7 as a white powder (1.10 g, 87\% yield). ${ }^{1} \mathrm{H}$ NMR (400 MHz, DMSO- $\left.d^{6}\right): \delta=8.59(\mathrm{t}, J=5.7 \mathrm{~Hz}, 2 \mathrm{H}), 8.54(\mathrm{~s}, 2 \mathrm{H}), 7.94-7.83(\mathrm{~m}, 4 \mathrm{H}), 3.24(\mathrm{q}, J=7.4,5.6 \mathrm{~Hz}, 4 \mathrm{H})$, $1.59(\mathrm{~h}, J=7.3 \mathrm{~Hz}, 4 \mathrm{H}), 0.94(\mathrm{t}, J=7.4 \mathrm{~Hz}, 6 \mathrm{H}) \mathrm{ppm} .{ }^{1} \mathrm{H} \mathrm{NMR}\left(400 \mathrm{MHz}, \mathrm{CDCl}_{3}\right): \delta=8.23(\mathrm{~d}, J=1.6 \mathrm{~Hz}, 2 \mathrm{H})$, $7.74(\mathrm{dd}, J=8.6,1.7 \mathrm{~Hz}, 2 \mathrm{H}), 7.61(\mathrm{~d}, J=8.6 \mathrm{~Hz}, 2 \mathrm{H}), 6.29(\mathrm{~s}, 2 \mathrm{H}), 3.51(\mathrm{q}, J=6.7 \mathrm{~Hz}, 4 \mathrm{H}), 1.72(\mathrm{~h}, J=7.4$ Hz, 4H), 1.05 (t, J = 7.4 Hz, 6H). ${ }^{13}$ C NMR (101 MHz, DMSO-d6): $\delta=166.30,165.76,156.31,131.54,122.99$, 122.33, 118.97, 112.34, 96.78, 41.17, 22.45, 11.52 ppm. HRMS (ESI): calcd for $\mathrm{C}_{22} \mathrm{H}_{23} \mathrm{~N}_{2} \mathrm{O}_{4}\left([\mathrm{M}+\mathrm{H}]^{+}\right)$: 379.1658; found: 379.1656. $\mathrm{R}_{\mathrm{f}}$ : 0.38 (DCM/MeOH 19:1).

Dipropyl benzofuro[2,3-b]benzofuran-2,9-dicarboxylate (8). Dicarboxylic acid 2 (0.12 g, $0.40 \mathrm{mmol})$ and potassium carbonate $\left(\mathrm{K}_{2} \mathrm{CO}_{3}\right)(0.22 \mathrm{~g}, 1.6 \mathrm{mmol}, 4$ equiv.) were suspended in anhydrous DMF (10 mL) in a flame-dried $50 \mathrm{~mL}$ two-neck round-bottom flask equipped with a reflux condenser, and purged with argon. Then, 1-bromopropane (0.11 mL, $1.2 \mathrm{mmol}, 3$ equiv.) was added dropwise, and 
the mixture was heated to reflux under vigorous stirring for $16 \mathrm{~h}$. Most of the DMF was then removed under reduced pressure at $60^{\circ} \mathrm{C}$, and the obtained residue was taken up in water $(20 \mathrm{~mL})$. The aqueous phase was extracted with EtOAc $(3 \times 20 \mathrm{~mL})$, the combined organic phases were washed once more with water $(20 \mathrm{~mL})$, and then dried with $\mathrm{MgSO}_{4}$. Upon slow evaporation of the solvent, colorless crystals of 8 suitable for X-ray analysis were obtained ( $0.05 \mathrm{~g}$, 33\% yield). ${ }^{1} \mathrm{H}$ NMR (400 $\mathrm{MHz}, \mathrm{CDCl}_{3}$ ): $\delta=8.58-8.51$ (m, 2H), 8.08 (dd, $J=8.8,1.8 \mathrm{~Hz}, 2 \mathrm{H}), 7.64(\mathrm{~d}, J=8.7 \mathrm{~Hz}, 2 \mathrm{H}), 4.37$ (t, $J=6.7 \mathrm{~Hz}, 4 \mathrm{H}), 1.88(\mathrm{~h}, J=7.2 \mathrm{~Hz}$, 4H), $1.10(\mathrm{t}, J=7.4 \mathrm{~Hz}, 6 \mathrm{H}) .{ }^{13} \mathrm{C} \mathrm{NMR}\left(101 \mathrm{MHz}, \mathrm{CDCl}_{3}\right): \delta=167.25,166.64,158.13,127.26,125.29$, $123.31,121.67,112.46,97.56,77.48,77.16,76.84,67.05,22.34,10.77$. HRMS (ESI): calcd for $\mathrm{C}_{22} \mathrm{H}_{20} \mathrm{O}_{6}$ $\left.([\mathrm{M}+\mathrm{H}]+]^{+}\right): 381.1338$; found: 381.1337 .

Poly(hexamethylene benzofurobenzofurandicarboxylate) (PA6B). A flame-dried $50 \mathrm{~mL}$ Schlenk flask was purged with argon and charged with hexamethylene diamine (105 mg, $0.900 \mathrm{mmol}$ ), dicarboxylic acid 2 (267 mg, $0.900 \mathrm{mmol}, 1.00$ eq.), anhydrous $N$-methylpyrrolidone (NMP) (3.3 mL), anhydrous pyridine (0.70 mL), triphenylphosphite (TPP) (0.480 mL, $1.81 \mathrm{mmol}, 2.01$ equiv.), and anhydrous lithium chloride ( $\mathrm{LiCl})(0.180 \mathrm{~g})$. The suspension was heated to $110^{\circ} \mathrm{C}$ under vigorous stirring, at which point it turned into a clear solution. After $4 \mathrm{~h}$, the solution was cooled to $50-60^{\circ} \mathrm{C}$, and poured into $\mathrm{MeOH}(50 \mathrm{~mL})$. The obtained white precipitate was filtered off, washed with hot $\mathrm{MeOH}$, and dried in vacuum to yield $301 \mathrm{mg}$ of the polyamide PA6B (88\% yield). ${ }^{1} \mathrm{H}$ NMR (400 MHz, acetone- $d^{6}$ ): $\delta$ = 7.18-7.01 (m, 2H), 6.74-6.53 (m, 4H), 5.99-5.85 (m, 2H), 2.70-2.48 (br, 4H), 0.93-0.73 (br, 4H), 0.700.50 (br, 4H). GPC (HFIP): $M_{\mathrm{n}}=77^{\prime} 100(\nexists=1.28)$. 


\section{Results and Discussion}

\section{Synthesis of Benzofuro[2,3-b]benzofuran Dicarboxylic Acid}

As part of our investigations on the incorporation of extended $\pi$-conjugated systems with optical or electronic properties into semiaromatic polyamides, we chose the benzofurobenzofuran (BFBF) as a model compound because of its synthetic accessability and structural similarity to organic semiconductor materials based on the benzothienobenzothiophene core that have been found to show excellent charge transport properties.9-12 The goal was to investigate whether the BFBF core is compatible with typical activation conditions for the polycondensation of aromatic dicarboxylic acids with diamines to yield the corresponding polyamides. Therefore, we first synthesized the benzofurobenzofuran dicarboxylic acid as a monomer. According to previously published procedures, the condensation reaction of glyoxal derivatives with two equivalents of $p$-substituted phenols under reflux in acidic media results in the formation of the corresponding dihydrobenzofurobenzofurans. ${ }^{17,18}$ Consistent with the literature, we thus obtained the $C_{\mathrm{s}}$-symmetric dihydrobenzofuro-benzofuran 1 when we reacted $p$-cresol with glyoxal sodium bisulfite. Nuclear magnetic resonance spectroscopy unambiguously proved that this reaction regioselectively furnished the 2,9-disubstituted dihydrobenzofuro[2,3-b] benzofuran 1 with a central ketal moiety, and not the 2,7-disubstituted dihydrobenzofuro[3,2-b]benzofurans. ${ }^{19}$

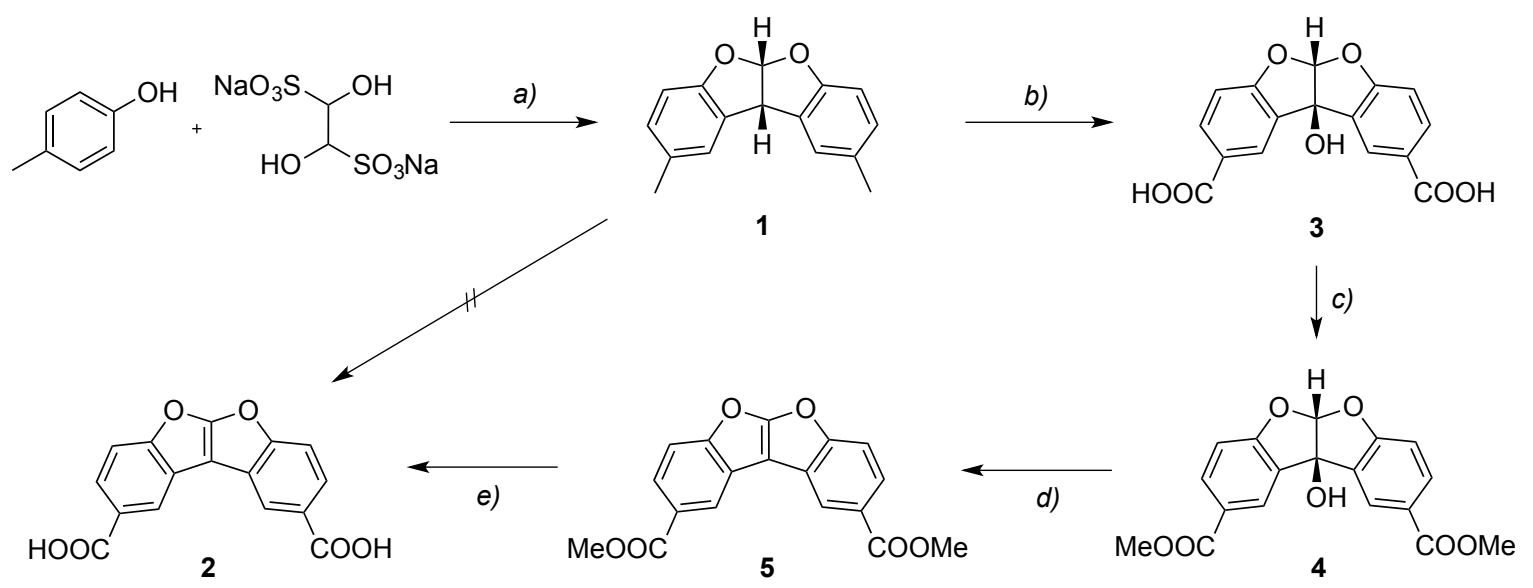

Scheme 2. Dimethyl dihydrobenzofurobenzofuran 1 was obtained by the acid-catalyzed reaction of $p$-cresol and glyoxal sodium bisulfite. Contrary to previous reports, 22,25 the oxidation of $\mathbf{1}$ with potassium permanganate did not yield the aromatic, $C_{2 \mathrm{v}}$-symmetric benzofurobenzofuran dicarboxylic acid $\mathbf{2}$ but its water adduct 3 that could not be straightforwardly dehydrated. Instead, we synthesized $\mathbf{2}$ by esterification of $\mathbf{3}$, dehydration with phosphoryl chloride, and ester cleavage. Reagents and conditions: a) $\mathrm{H}_{2} \mathrm{SO}_{4}$ (conc.), $\mathrm{AcOH} / \mathrm{H}_{2} \mathrm{O}$, reflux, 3 h, 35\%; b) $\mathrm{KMnO}_{4}$, pyridine/ $\mathrm{H}_{2} \mathrm{O}$, reflux, $5 \mathrm{~h}, 86 \%$; c) $\mathrm{HCl} / \mathrm{MeOH}, \mathrm{reflux}, 16 \mathrm{~h}$, $90 \%$; d) $\mathrm{POCl}_{3}$, pyridine, $0^{\circ} \mathrm{C}$ to room temperature, $2 \mathrm{~h}, 83 \%$; e) $\mathrm{LiOH}, \mathrm{THF} / \mathrm{H}_{2} \mathrm{O}$, reflux, $3 \mathrm{~h}, 89 \%$. 
a)
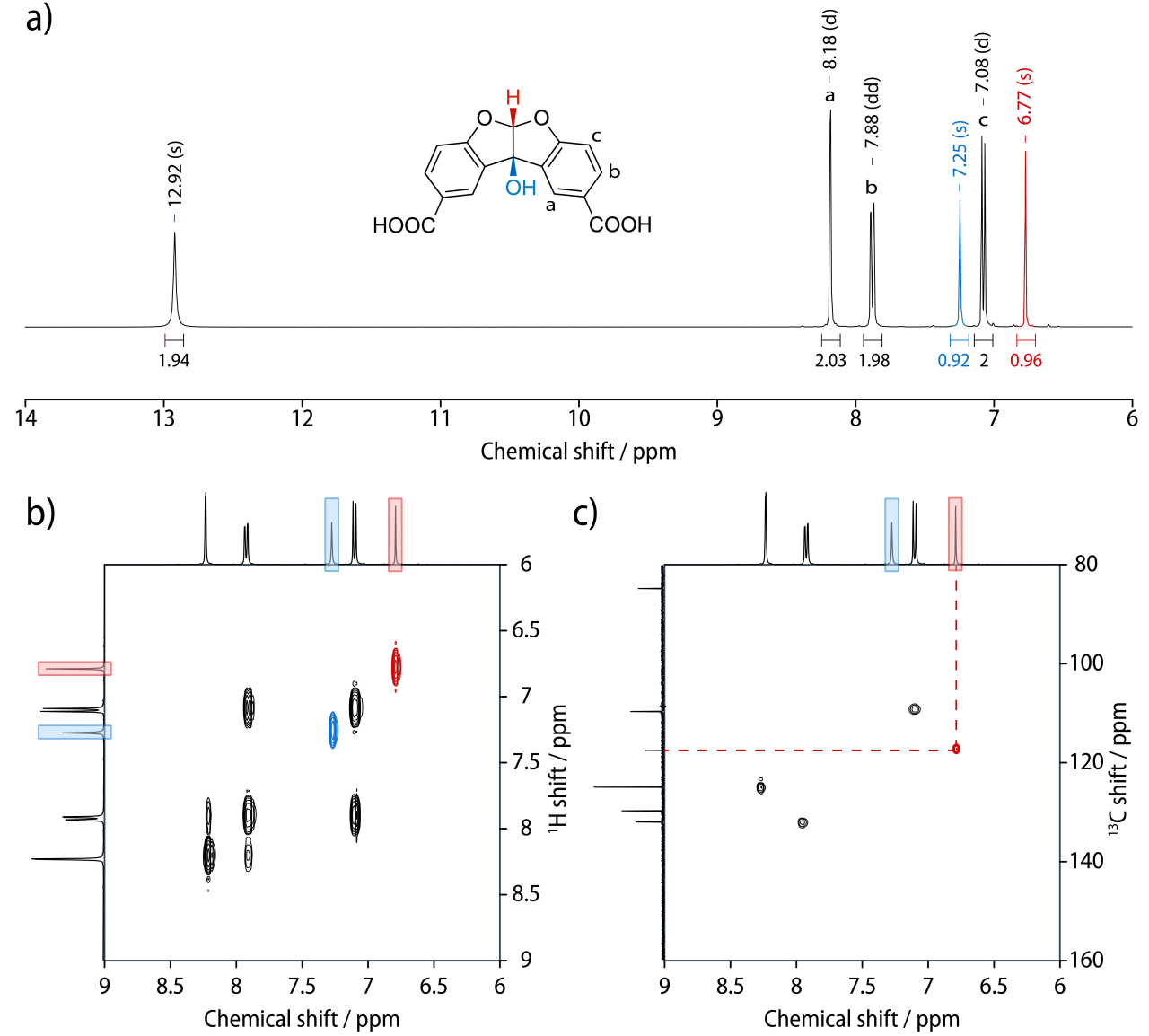

Figure 1. a) ${ }^{1} \mathrm{H}$ NMR spectra, b) ${ }^{1} \mathrm{H}-1 \mathrm{H}$ COSY NMR spectra, and $\left.c\right)^{1}{ }^{\mathrm{H}}-{ }^{13} \mathrm{C}$ HSQC NMR spectra of 3 . The ${ }^{1} \mathrm{H}$ NMR spectrum showed five distinct peaks in the region 6.7-8.2 ppm and the signal for the carboxylic acid protons at 12.9 ppm, integrating to 1:2:1:2:2:2. The two singlets at $6.77 \mathrm{ppm}$ (red) and $7.25 \mathrm{ppm}$ (blue) did not show off-diagonal peaks in the COSY NMR spectrum. The proton at $7.25 \mathrm{ppm}$ was not correlated to a carbon atom according to the HSQC spectrum.

Previous reports suggested that the oxidation of $\mathbf{1}$ with potassium permanganate would straightforwardly furnish the $C_{2 \mathrm{v}}$-symmetric aromatic benzofurobenzofuran dicarboxylic acid 2 (Scheme 2). ${ }^{22,25}$ However, we found that the product of this reaction was the non-planar, non-aromatic, hydrated dicarboxylic acid $\mathbf{3}$ instead. This result was not due to a different outcome of the reaction in our hands, but due to an incorrect interpretation of the analytical data in the literature. For instance, the ${ }^{1} \mathrm{H}$ NMR spectrum of the product was identical to the one reported previously, with five distinct peaks (three singlets and two duplets) in the region 6.7-8.2 ppm and a peak at $12.9 \mathrm{ppm}$ for the carboxylic acid protons (Figure 1a). ${ }^{22}$ Hence, neither the number of peaks nor their multiplicities or their integration of 1:2:1:2:2:2 for a total of 10 protons were in agreement with the reported structure of 2 but consistent with the structure of its water adduct 3 , which is also proven by a combination of ${ }^{1} \mathrm{H}-{ }^{1} \mathrm{H}$ COSY (Figure $1 b$ ) and ${ }^{1} \mathrm{H}^{-13} \mathrm{C}$ HSQC (Figure 1c) 2D-NMR experiments. The COSY experiments revealed 
that, while the peaks at $8.18,7.88$ and $7.08 \mathrm{ppm}$ corresponded to the aromatic protons, the singlets at 7.25 and $6.77 \mathrm{ppm}$ were not correlated to any other protons. Moreover, HSQC NMR spectroscopy indicated that the proton at $6.77 \mathrm{ppm}$ coupled with the carbon atom at $118 \mathrm{ppm}$, whereas the proton signal at $7.25 \mathrm{ppm}$ was not correlated with any carbon in the molecule at all. Furthermore, the molecular ion peak in MALDI-ToF mass spectrometry (Supplementary Figure S1) was consistent with the mass of the water adduct 3, of which the structure was ultimately proven by single-crystal X-ray structure analysis (see below).

All attempts to dehydrate compound $\mathbf{3}$ directly, in order to obtain the completely aromatic benzofurobenzofuran dicarboxylic acid 2 were unsuccessful. Performing the reaction in neat $\mathrm{SOCl}_{2}$ required heating at reflux for the reaction to start, but product degradation occurred within less than $30 \mathrm{~min}$. Upon addition of sulfuric acid $\left(\mathrm{H}_{2} \mathrm{SO}_{4}\right)$ to 3 , either as a catalyst or as the reaction solvent, an immediate decomposition of the starting material was observed. Heating $\mathbf{3}$ in phosphoric acid $\left(\mathrm{H}_{3} \mathrm{PO}_{4}\right)$ appeared to result in an opening of the heterocycles according to proton and carbon NMR. Since the dehydration of $\mathbf{3}$ was impossible to achieve, one might have considered the dehydrogenation of $\mathbf{1}$ before oxidation, following a bromination-dehydrohalogenation route that had already been used for similar molecules. ${ }^{37-39}$ However, this approach had already been shown to not work in the specific case of compound 1.40

On the other hand, dehydrations of alcohols at low temperatures have often been reported to work efficiently using chlorinating agents such as phosphoryl chloride $\left(\mathrm{POCl}_{3}\right)$ or thionyl chloride $\left(\mathrm{SOCl}_{2}\right)$ when the compounds are soluble in chlorinated solvents or pyridine. ${ }^{41}$ Therefore, we subjected $\mathbf{3}$ to heating to reflux in $\mathrm{MeOH} / \mathrm{HCl}$ overnight in order to obtain the corresponding dimethyl ester 4, which exhibited a significantly improved solubility in organic solvents. This diester was subsequently dehydrated using an excess of $\mathrm{POCl}_{3}$ in pyridine at $0^{\circ} \mathrm{C}$ to yield the completely aromatic dimethyl benzofurobenzofuran dicarboxylate 5. Saponification of $\mathbf{5}$ using an excess of lithium hydroxide (LiOH) in THF/water mixture upon heating to reflux overnight eventually furnished the desired aromatic benzofurobenzofuran dicarboxylic acid 2 . Hence, three additional steps were necessary to dehydrate the dicarboxylic acid 3, which nevertheless could be synthezised in a good yield of $66 \%$ over all three steps. The comparison of the proton NMR spectra of dicarboxylic acids $\mathbf{3}$ and $\mathbf{2}$ showed the disappearance of the two singlets of the $\mathrm{CH}$ and hydroxyl groups (Figure $2 a$ ). The remaining three 
aromatic peaks, associated to the three different couples of aromatic protons, were additionally shifted downfield by respectively $0.62,0.12$ and $0.81 \mathrm{ppm}$ (Figures $2 a$ and $b$ ). This observation was consistent with the aromatization of the molecule upon dehydration. Negative-mode high-resolution MALDI-ToF mass spectrometry was found to match the desired dicarboxylic acid 2 (Supplementary Figure S2).

a)

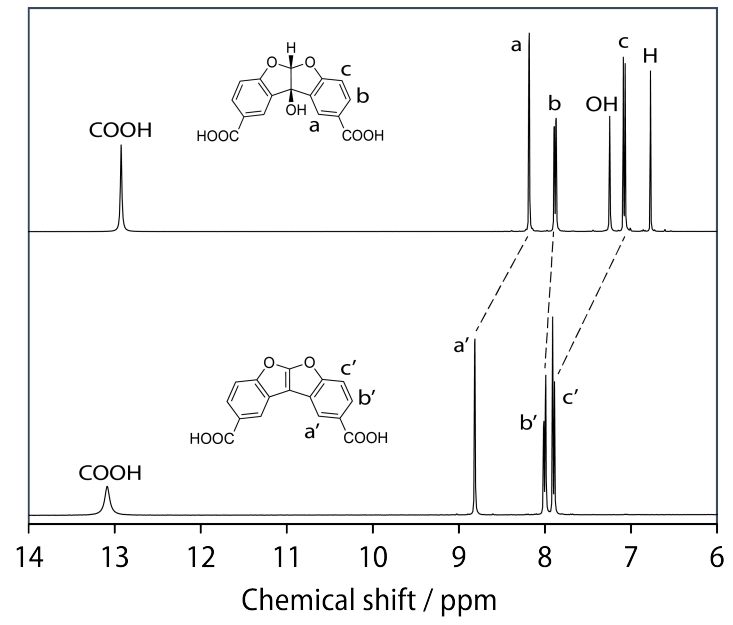

b)

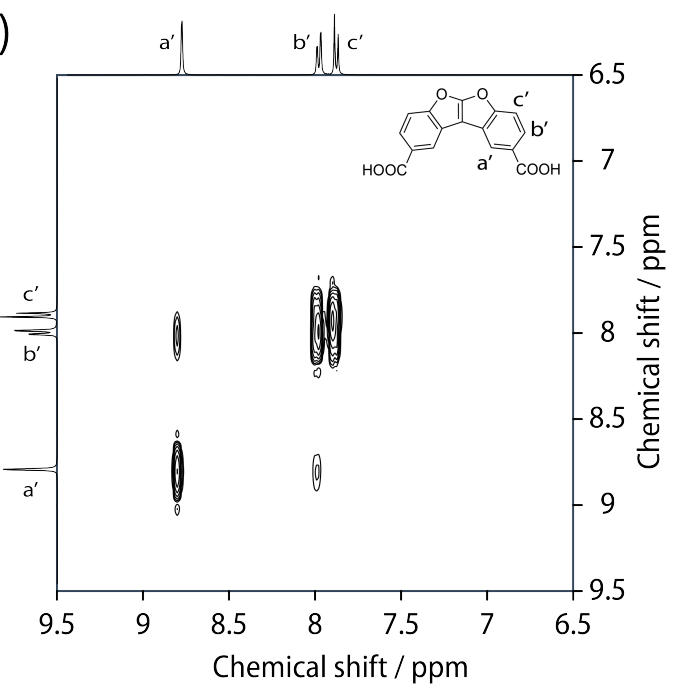

Figure 2. a) Comparison of the proton NMR spectra of dicarboxylic acids $\mathbf{3}$ (top) and $\mathbf{2}$ (bottom), both recorded in DMSO-d6. The two singlets associated to the water adduct disappeared and the three couple of aromatic protons were shifted downfield, consistent with the aromatization of the molecule. b) The ${ }^{1} \mathrm{H}-{ }^{1} \mathrm{H}$ COSY NMR spectrum of $\mathbf{2}$ helped to unambiguously assign the $\mathrm{b}^{\prime}$ and c' protons.

\section{X-ray Structure Analysis}

In order to better understand the packing behavior of both the benzofurobenzofuran cores and their hydrated derivatives in the corresponding polyamides, different model compounds were synthesized and investigated by single-crystal X-ray structure analysis. To this end, we converted the hydrated benzofurobenzofuran dicarboxylic acid into the corresponding dipropyl dicarboxamide 6 using ethyl dimethylaminopropyl carbodiimide (EDCI) and hydroxybenzotriazol (HOBt) as the coupling reagents (Scheme 4a). Recrystallization of 6 from hot ethanol allowed us to obtain single crystals suitable for Xray structure analysis. Moreover, we prepared the diamide $\mathbf{7}$ as well as the diester $\mathbf{8}$ of the benzofurobenzofuran dicarboxylic acid 2 by an EDCI/HOBt-promoted coupling with propylamine and a nucleophilic substitution reaction with 1-bromopropane, respectively. While various attempts towards the recrystallization of $\mathbf{7}$ remained unsuccessful, single crystals of the diester $\mathbf{8}$ were obtained upon slow evaporation of a solution in EtOAc at room temperature. 
<smiles>CCCCN</smiles><smiles>CCCNC(=O)c1ccc2c(c1)C1Oc3ccc(C(=O)NCCC)cc3C1(O)O2</smiles>
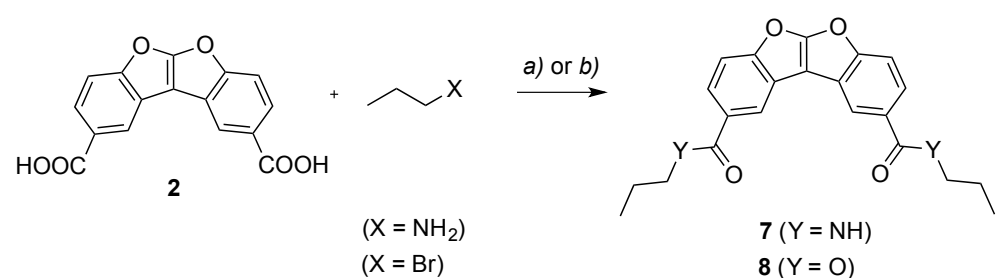

Scheme 3. Synthesis of the benzofurobenzofuran dicarboxamide $(6,7)$ and diester $(8)$ derivatives. Reagents and conditions: a) EDCI, HOBt, DIPEA, DMF, room temperature, $16 \mathrm{~h}, 42-87 \%$ b) $\mathrm{K}_{2} \mathrm{CO}_{3}$, DMF, $70^{\circ} \mathrm{C}, 16 \mathrm{~h}, 33 \%$.

a)

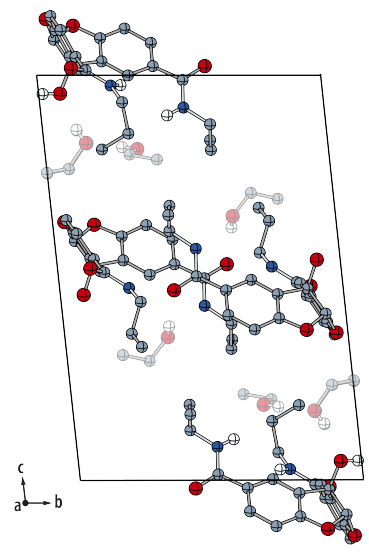

b)

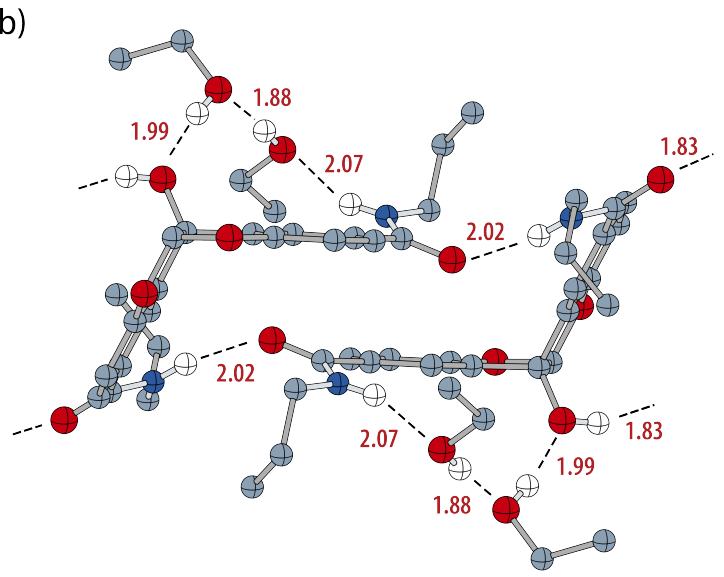

c)

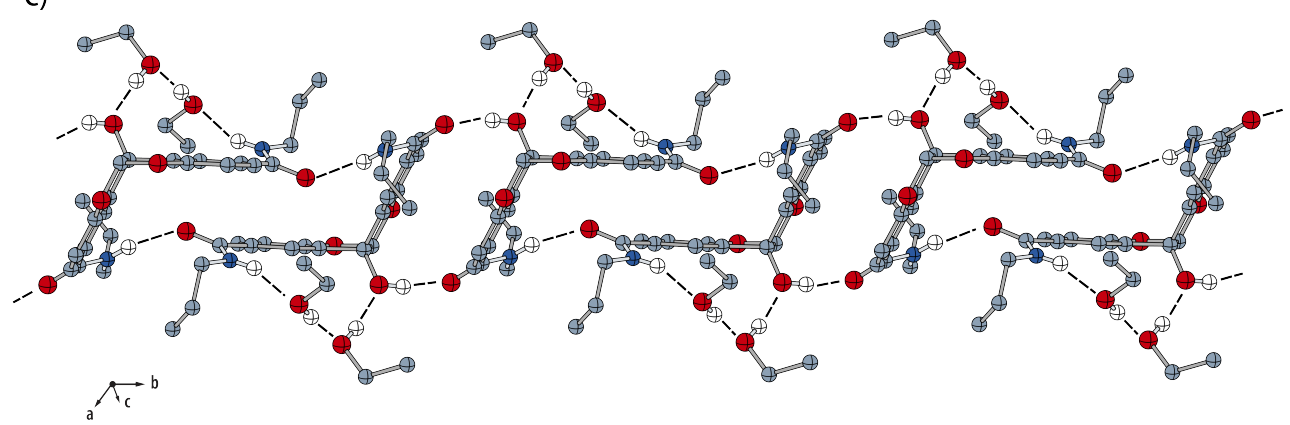

Figure 3. Ball-and-stick representations of the single-crystal X-ray structure of 6 (CCDC 1528255) $a$ ) Representation of the unit cell of 6; the included ethanol molecules are rendered semi-transparent for clarity. b) Hydrogen bond distances (in Ångstroms).c) Illustration of the one-dimensional hydrogen bonding network along the crystallographic $b$-axis; all hydrogen atoms except those that participate in hydrogen bonding have been omitted for clarity.

The hydrated dicarboxamide derivative 6 crystallized in the form of colorless, needle-like crystals in the triclinic unit cell P-1 with the lattice parameters $a=10.19 \AA, b=13.71 \AA, c=19.07 \AA, \alpha=90.8^{\circ}, \beta=103.3^{\circ}$, and $\gamma=109.9^{\circ}$ (Figure $3 a$ ). The unit cell consists of four molecules of 6 and six ethanol molecules. The molecule exhibits a non-planar structure with an angle of $116.7^{\circ}$ between the planes of the furan rings, 
similar to related heterocyclic compounds reported previously. ${ }^{42,43}$ Each dicarboxamide molecule participates in six intermolecular hydrogen bonds (Figure $3 b$ ) involving the amide groups, the central hydroxyl function, and two of the three independent ethanol molecules, which in turn generates a onedimensional hydrogen bonding network along the crystallographic $b$-axis (Figure $3 c$ ).

Similar to 6, the diester $\mathbf{8}$ gave rise to colorless, needle-like crystals and crystallized in the triclinic space group P-1 with the lattice parameters $a=8.76 \AA, b=10.38 \AA, c=11.17 \AA, \alpha=63.1^{\circ}, \beta=82.8^{\circ}$, and $\gamma=$ $86.3^{\circ}$ (Figure $4 a$ ). In the crystal structure, the benzofurobenzofuran core of 8 contrary to 6 exhibits an almost perfect planar structure, as shown by the torsion angles $\mathrm{C}(18)-\mathrm{C}(11)-\mathrm{C}(12)-\mathrm{O}(3)=-179.59(9)^{\circ}$ and $\mathrm{C}(9)-\mathrm{C}(11)-\mathrm{C}(12)-\mathrm{O}(4)=179.24(9)^{\circ}$. The benzofurobenzofuran 8 is arranged into layers within which all molecules have the same orientation, and a $180^{\circ}$ rotated orientation between alternating layers. These layers form pairs that can be described by a parallel-displaced $\pi$-stacked arrangement within the centrosymmetric dimers A-B (Figure $4 b$ ) with an overlap equating to one of the benzofuran moieties. The interaction between these layer pairs is characterized by the centrosymmetric dimers BC that have a much smaller overlap. The interlayer distances both within and between the layer pairs are $3.3 \AA$, which is approximately equal to the sum of van der Walls radii of two carbons and significantly smaller than the one observed in benzothieno[2,3-b]benzothiophene (3.58 $\AA^{4}{ }^{44}$ Consequently, intermolecular $\mathrm{C} \cdots \mathrm{O}$ and $\mathrm{C} \cdots \mathrm{C}$ short contacts at distances of $3.35 \AA$ and $3.33 \AA$ were observed, respectively (Figure 4c). A closer packing had previously been reported also for herringbone arrangements of certain oligofurans as compared to the corresponding oligothiophenes. 45
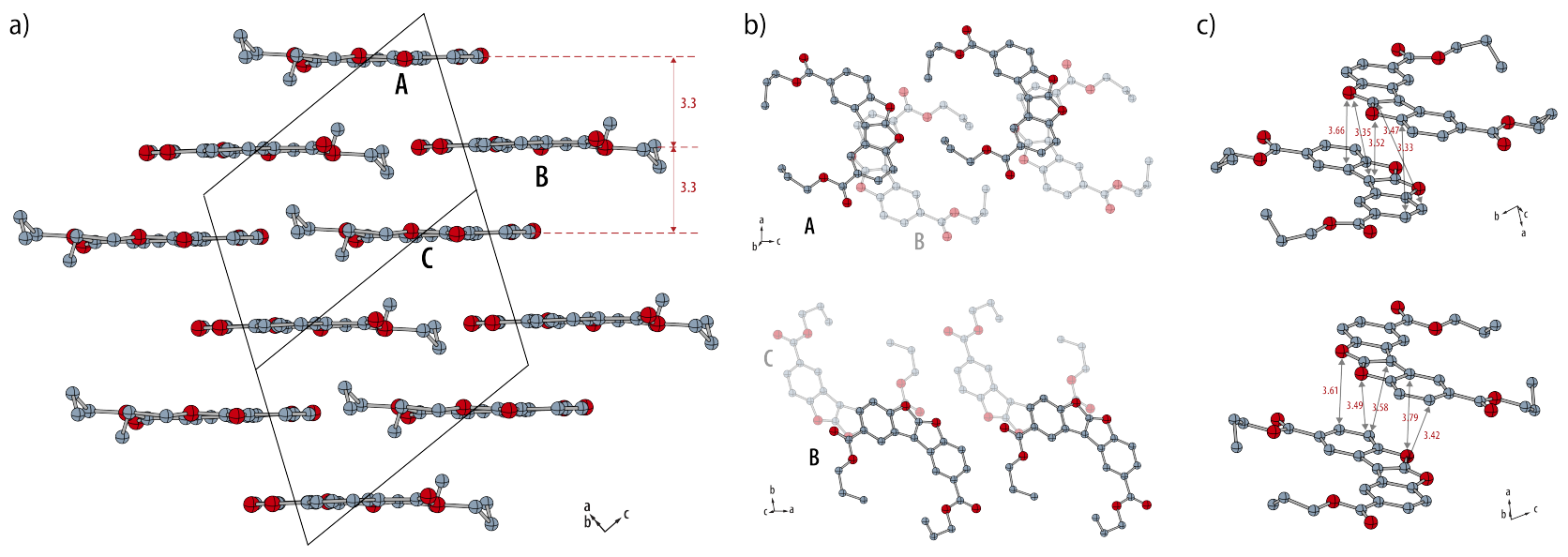

Figure 4. Ball-and-stick representations of the single-crystal X-ray structure of 8 (CCDC 1528254) a) Representation of the unit cell of $\mathbf{8}$ including the interlayer distances. b) Top view of the two types of centrosymmetric dimers and $c$ ) an illustration of short contacts and distances (in Ångstroms); all hydrogen atoms omitted for clarity. 
The benzofurobenzofuran dicarboxylic acid $\mathbf{2}$ was incorporated into the semiaromatic polyamide PA6B by solution-phase polycondensation with hexamethylene diamine using Yamazaki-Higashi conditions (Scheme 4).46-48 The obtained polyamide was found to be insoluble in most common organic solvents, but partially soluble in hot dimethylsulfoxide (DMSO) and well soluble in 1,1,1,3,3,3hexafluoropropane-2-ol (HFIP, $40 \mathrm{mg} / \mathrm{mL}$ ).

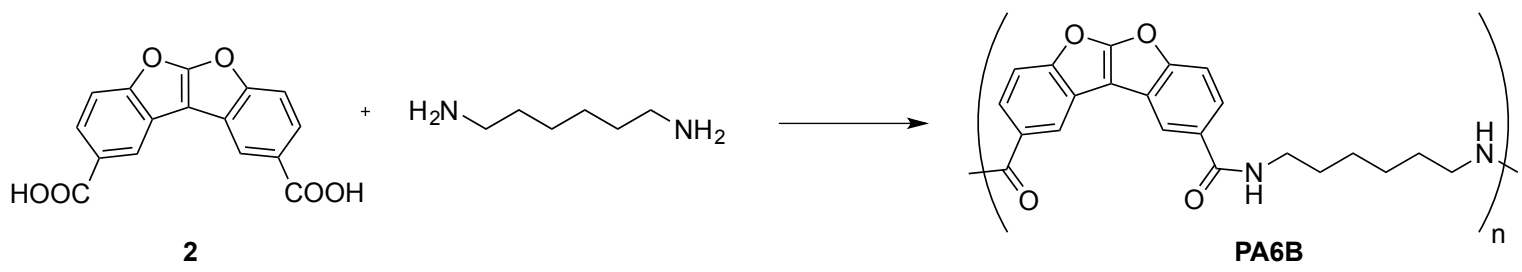

Scheme 4. Synthesis of poly(hexamethylene benzofurobenzofurandicarboxylate) (PA6B) using Yamazaki-Higashi conditions: $\mathrm{TPP}, \mathrm{LiCl}$, pyridine/NMP (1:5), $110^{\circ} \mathrm{C}, 4 \mathrm{~h}, 88 \%$.

Both ${ }^{1} \mathrm{H}$ NMR (Figure $5 a$ ) and solid-state infrared spectroscopy (Figure $5 b, c$ ) indicated the successful conversion into a polyamide. Indeed, the peak positions and integration in the ${ }^{1} \mathrm{H}$ NMR spectra matched the structure of the expected polyamide, and the amide protons could be clearly observed at $5.92 \mathrm{ppm}$. Moreover, small additional signals were visible in the aromatic region that we assigned to the aromatic protons of the BFBF carboxylic acid end groups. Since no amine end groups could be detected, the integration of the aromatic end group signals relative to those of the repeating units would translate into a molecular weight of $M_{\mathrm{n}}=10^{\prime} 900$ (degree of polymerization $P_{\mathrm{n}}=29$ ), which is in reasonable agreement with the molecular weight of $M_{\mathrm{n}}=7^{\prime} 100(\nexists=1.28)$ determined by gel permeation chromatography in HFIP.

In the IR spectra, the broad absorption at $2700-3500 \mathrm{~cm}^{-1}$ that can be assigned to the $\mathrm{O}-\mathrm{H}$ stretching vibration as well as the sharper band at $1692 \mathrm{~cm}^{-1}$ corresponding to the $\mathrm{C}=0$ stretching vibration of a free carboxylic acid group completely disappeared upon polycondensation. Instead, five new peaks were observed at $3311,2931,2857,1619$, and $1540 \mathrm{~cm}^{-1}$ that can be attributed to the amide A, asymmetric $\mathrm{CH}_{2}$ stretching, symmetric $\mathrm{CH}_{2}$ stretching, amide I, and amide II bands of the semiaromatic polyamide, respectively. 
a)
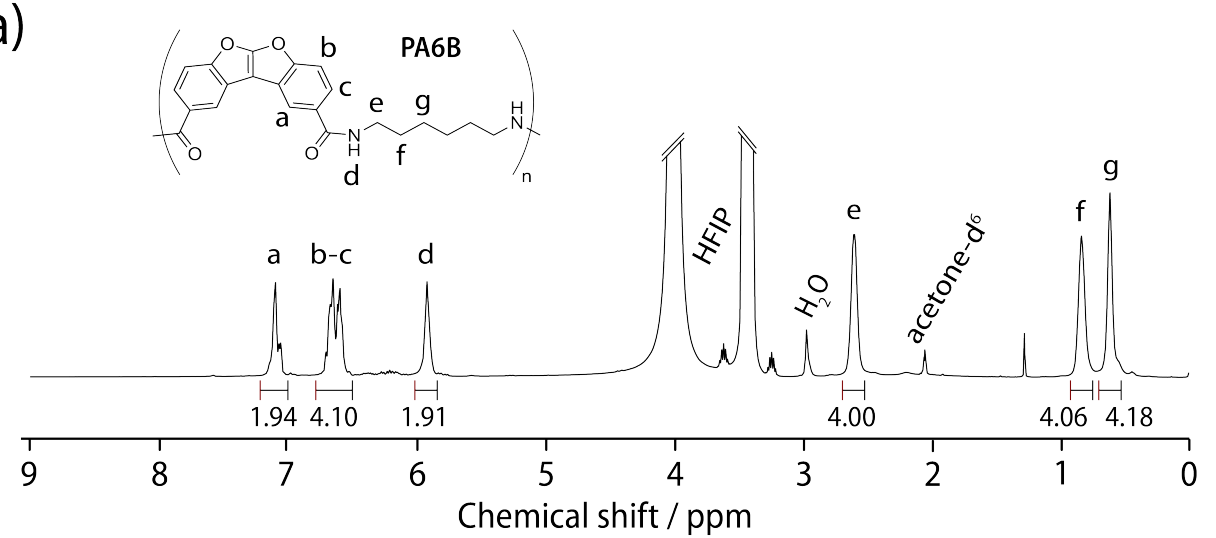

b)

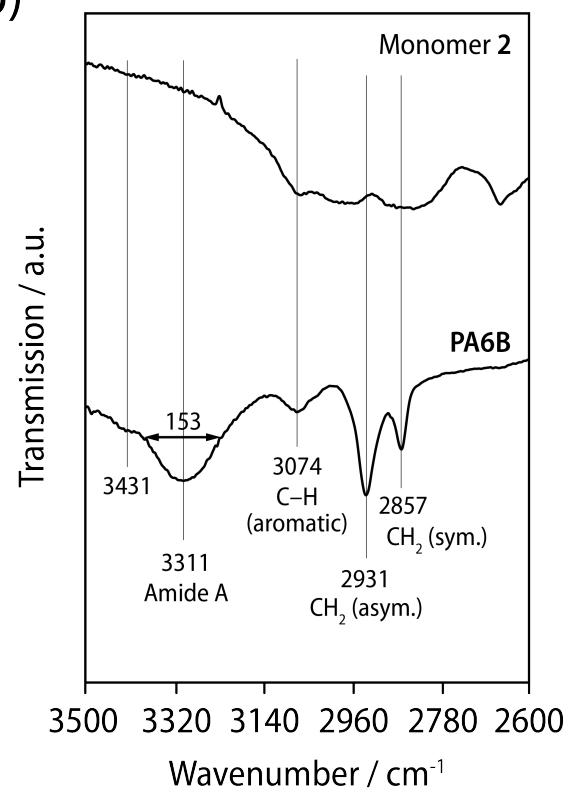

c)

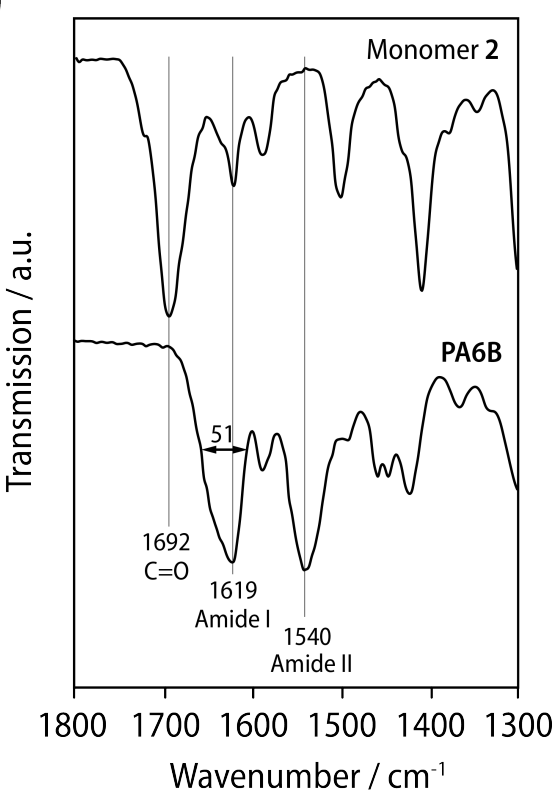

Figure 5. a) ${ }^{1} \mathrm{H}-\mathrm{NMR}$ spectrum of the semiaromatic PA6B recorded in HFIP/acetone- $d^{6}$. The amide protons of the repeating unit are visible at $5.92 \mathrm{ppm} . \mathrm{b}, c$ ) Comparison of the solid-state IR spectra of the dicarboxylic benzofurobenzofuran monomer 2 and the semiaromatic polyamide PA6B. Both the band at $1692 \mathrm{~cm}^{-1}(\mathrm{C}=\mathrm{O})$ and the broad absorption at $2700-3500 \mathrm{~cm}^{-1}(\mathrm{O}-\mathrm{H})$ of the dicarboxylic acid disappeared after polycondensation. The concomitant appearance of the three characteristic amide I, II and A bands (1540, 1619 and $3311 \mathrm{~cm}^{-1}$ respectively) as well as the symmetric and asymmetric $\mathrm{CH}_{2}$ stretching vibrations of the diamine repeating units ( 2857 and $2931 \mathrm{~cm}^{-1}$ ) indicated that the polycondensation was successful. The broadness of both amide I and amide A bands (FWHM of 51 and $153 \mathrm{~cm}^{-1}$ respectively) can be attributed to the amorphous character of the polyamide.

The main amide $\mathrm{A}$ band at $3311 \mathrm{~cm}^{-1}$ and its shoulder at $3431 \mathrm{~cm}^{-1}$ can be assigned to the $\mathrm{N}-\mathrm{H}$ stretching vibrations of hydrogen-bonded and free amide groups, respectively. The peak position as well as the full width at half maximum (FWHM) of $153 \mathrm{~cm}^{-1}$ were in good agreement with what had been reported for other, completely amorphous semiaromatic polyamides, ${ }^{49}$ while a more red-shifted peak maximum and a smaller FWHM should be expected in the case of a semi-crystalline polyamide. ${ }^{50}$ Similarly, the amide I band exhibited a FWHM of $51 \mathrm{~cm}^{-1}$, which is larger than what is typically observed in semicrystalline 
polyamides, and was actually composed of two distinct peaks at 1645 and $1619 \mathrm{~cm}^{-1}$ that became evident in a plot of the second derivative of the spectrum (Supplementary Figure S3) and were, again, assigned to the carbonyl stretching vibrations of the free and the hydrogen-bonded amide groups in amorphous polyamides, respectively. ${ }^{50}$ The amorphous character of PA6B was further confirmed by wide-angle X-ray scattering measurements (WAXS), since no crystalline peak could be observed (Supplementary Figure S4).

Accordingly, no melting transitions were observed for the polyamide PA6B in differential scanning calorimetry (DSC) or modulated DSC. The polymer exhibited a glass transition temperature $\left(T_{\mathrm{g}}\right)$ at $205^{\circ} \mathrm{C}$ (Figure $6 a$; Supplementary Figure S5), which is significantly higher than the $T_{\mathrm{g}} \leq 130^{\circ} \mathrm{C}$ of typical semiaromatic polyamides based on terephthalic and/or isophthalic acid.51 The high $T_{\mathrm{g}}$ value for PA6B may be accounted for by the presence of the rigid fused heterocyclic groups in the chain backbone, consistent with estimates from group contribution theory. ${ }^{22}$ No melting transition could be observed since the polymer was found to degrade at temperatures above the $T_{\mathrm{g}}$ (Figure $6 a$ ). Thermogravimetric analysis (Figure $6 b$ ) showed that this degradation started at about $240^{\circ} \mathrm{C}$ and was associated with only a minor mass loss, suggesting that it may be related to reactions of the heterocyclic cores. A second, major decomposition step was observed at temperatures above $400^{\circ} \mathrm{C}$ in air.

a)

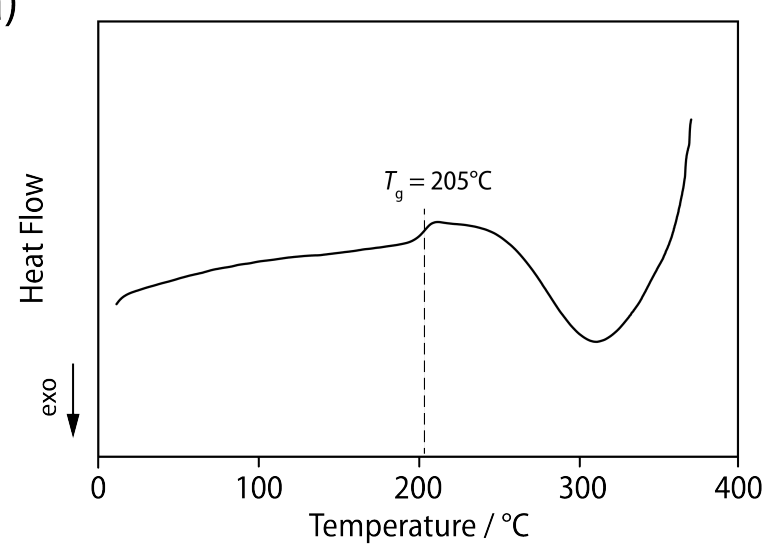

b)

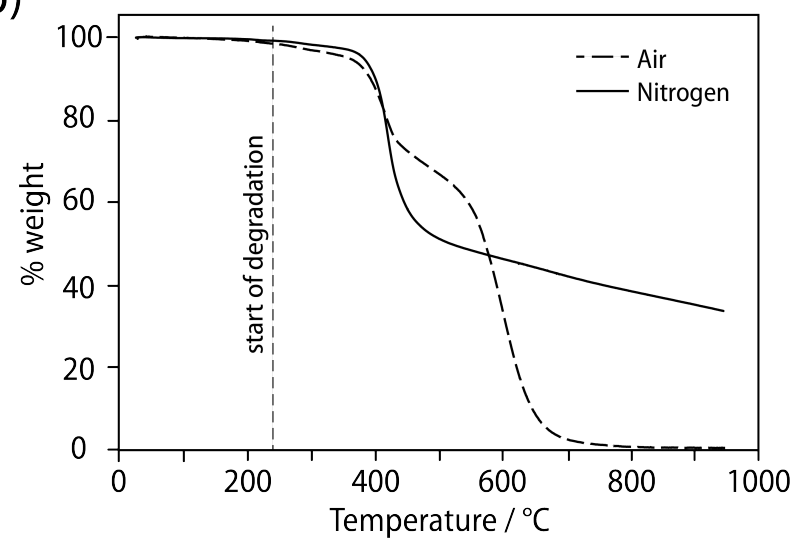

Figure 6. a) Second heating scan in differential scanning calorimetry (DSC) of PA6B indicated thermal degradation at temperatures above the glass transition temperature $\left(T_{\mathrm{g}}=205^{\circ} \mathrm{C}\right) \mathrm{b}$ ) Thermogravimetric analysis (TGA) scans of PA6B in air (dashed line) and nitrogen (solid line).

Fused benzothiophenes have recently been shown to exhibit excellent semiconducting properties, ${ }^{9-16}$ while organic semiconductors based on related benzofurans have more recently been reported, as well.20,21 Therefore, the structural similarity of the benzofurobenzofuran core to 
benzothienobenzothiophene (BTBT) indeed called for an investigation of the optoelectronic properties of films of the benzofurobenzofuran polyamide PA6B as well as the corresponding dicarboxamide model compound 7. UV/vis absorption spectroscopy of the polyamide PA6B or $\mathbf{7}$ in HFIP solutions showed an absorption band at an absorption maximum at $237 \mathrm{~nm}$ with a shoulder at $269 \mathrm{~nm}$ (Figure 7a, solid lines). Moreover, thin films obtained from dropcasting PA6B or $\mathbf{7}$ onto quartz substrates revealed similar spectral absorption characteristics, i.e., an absorption maximum at $244 \mathrm{~nm}$ and an additional shoulder at $276 \mathrm{~nm}$ (Figure $7 a$, dashed lines). The slight shift of $7 \mathrm{~nm}$ between solution-phase and thin film measurements can be attributed to a solid-state red shift.

Computations revealed a non-trivial excited state behavior of the dimethylcarboxamide 9 (used as a proxy for PA6B or 7) arising from energetically close lying excited states. The first five transition energies as well as their oscillator strengths based on consistent excited state computations with TDDFT (PBE0 functional using Tamm-Doncoff approximation) and ADC(2) have been assigned and are listed in the Supporting Information (Supplementary Table S1). The HOMO-LUMO transition that primarily contributes to the highest wavelength optical band at $269 \mathrm{~nm}$ as well as the HOMO-(LUMO+2) transition with an energy gap corresponding to the most intense optical band at $237 \mathrm{~nm}$ were identified as the brightest transitions. Electron density differences for each transition reveal the strong $\pi-\pi^{*}$ character with a remarkable shift of electron density from the central enediol-type double bond into the neighboring benzene units, indicating the break-up of conjugation in the dominant excited states (Figure $7 b$; Supplementary Figure S6). This fact, along with the comparably large HOMO-LUMO gap of $5.08 \mathrm{eV}$, renders charge transport in the $C_{2 \mathrm{v}}$-BFBF-based materials significantly more difficult than in the corresponding BTBT counterparts. In agreement with this assessment, field-effect transistors fabricated from thin films of either the polyamide PA6B or the model compound $\mathbf{7}$ showed no charge transport across the thin films, neither in bottom-gate bottom-contact nor in bottom-gate top-contact configurations. We attribute this observation in particular to the fact that both the very low-lying HOMO $(-6.36 \mathrm{eV})$ and the high-lying LUMO $(-1.28 \mathrm{eV})$ are energetically strongly mismatched with the utilized gold source/drain electrodes (work function $\approx 5 \mathrm{eV}$ ), 53 which makes an efficient charge carrier injection into the BFBF-films energetically unfavorable. 
a)

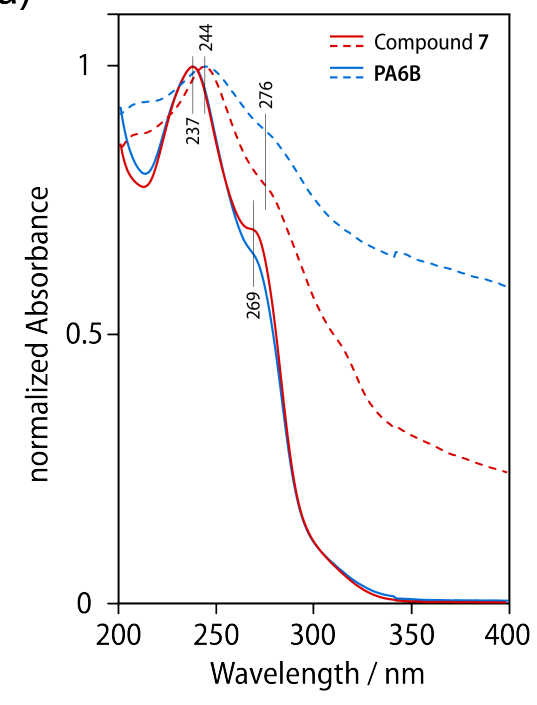

b)

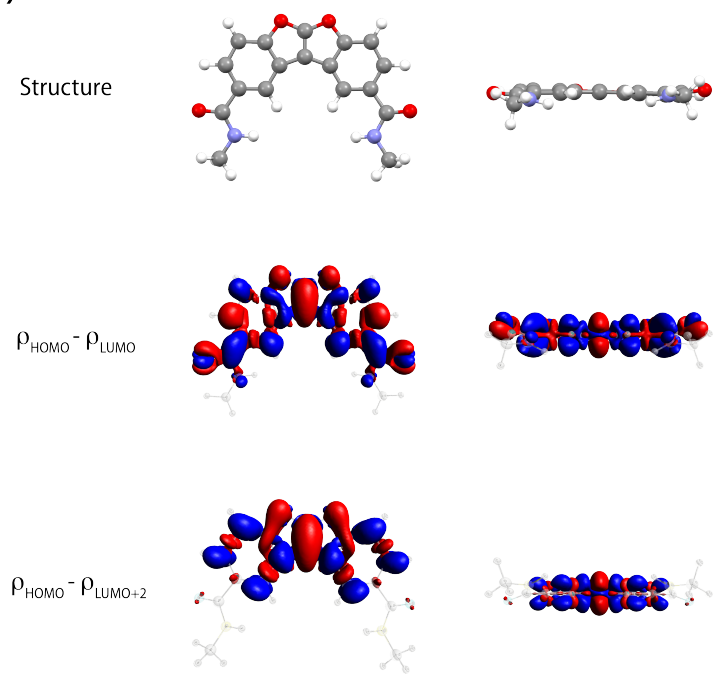

Figure 7. a) Normalized UV/vis absorption spectra of solutions (solid lines) and thin films (dashed lines) of PA6B and the model compound 7 measured at $25^{\circ} \mathrm{C}$ b) Density differences at the $\operatorname{ADC}(2) /$ def2-SVP level for the corresponding dimethyl carboxamide 9 in its first and fifth singlet excited-state PBE/def2-SVP optimized geometry. Isodensities $=-0.0005$ (red) and +0.0005 (blue).

\section{Conclusion}

In conclusion, we have developed the synthesis of a benzofurobenzofuran (BFBF) building block for its inclusion in semiaromatic polyamides, aiming at investigating the thermal and optoelectronic properties of the resulting polyamides. The fused benzofuran-based cores were chosen because of the straightforward synthetic accessibility of $C_{2 \mathrm{v}}$-symmetric $\mathrm{BFBF}$ monomers and their molecular resemblance to benzothienobenzothiophenes, which had previously been shown to be efficient semiconductors that exhibit high carrier mobilities.

We first established a synthetic route that furnished the desired benzofurobenzofuran dicarboxylic acid monomer in a total yield of $20 \%$ on the multi-gram scale, starting from commercial precursors. Moreover, we analyzed the packing behavior of the benzofuran derivatives in the solid state by means of X-ray structure analysis. The corresponding semiaromatic polyamide PA6B was then obtained by the solution-phase polycondensation of the BFBF dicarboxylic acid with hexamethylene diamine under Yamazaki-Higashi conditions. The rigidity of the fused benzofuran core resulted in a high $T_{\mathrm{g}}$ of $205^{\circ} \mathrm{C}$, whereas decomposition occurred already at around $240^{\circ} \mathrm{C}$. Although previous research had demonstrated that amide hydrogen bonding did not constitute a general impediment to charge transport in organic semiconductors, ${ }^{54-60}$ field-effect transistors fabricated from thin films of either the 
model compound $\mathbf{7}$ or the polyamide PA6B showed no charge transport. However, our investigations by IR spectroscopy and WAXS had revealed that PA6B thin films were completely amorphous. Moreover, molecular computations revealed a strong mismatch of both the HOMO and the LUMO level with the work function of the gold electrodes, as well as a significant shift of electron density from the central enediol-type double bond of the BFBF moiety into the neighboring benzene units upon excitation, resulting in the break-up of conjugation in the dominant excited states. All of these factors may be the reason why the charge transport properties of the BFBF-based materials were inferior. Nevertheless, our results demonstrate that polyamides comprising extended $\pi$-conjugated systems from fused heterocycles can be straightforwardly prepared using Yamazaki-Higashi polycondensation conditions, which may stimulate further research on the way towards polyamide-based semiconductors from better suited chromophores in the future.

\section{Acknowledgments}

The authors gratefully acknowledge funding from the Schweizerischer Nationalfonds (SNF grant 156001) and the the Kommission für Technologie und Innovation (KTI Project 15503.1 PFIW-IW). D.G. acknowledges support from the 'EPFL Fellows' fellowship programme co-funded by Marie SkłodowskaCurie, Horizon 2020 Grant agreement no. 291771.

\section{References}

(1) Marchildon, K. Macromol. React. Eng. 2011, 5 (1), 22.

(2) Zhang, G.; Zhou, Y.-X.; Kong, Y.; Li, Z.-M.; Long, S.-R.; Yang, J. RSC Adv. 2014, 4, 63006.

(3) Zhang, C.; Huang, X.; Zeng, X.; Cao, M.; Cai, T.; Jiang, S.; Yi, Q. J. Appl. Polym. Sci. 2013, 131 (7), 40058.

(4) Novitsky, T. F.; Lange, C. A.; Mathias, L. J.; Osborn, S.; Ayotte, R.; Manning, S. Polymer 2010, 51 (11), 2417.

(5) Garcia, J. M.; Garcia, F. C.; Serna, F.; la Pena, de, J. L. Progress in Polymer Science 2010, 35 (5), 623.

(6) Ahmed, D.; Hongpeng, Z.; Haijuan, K.; Jing, L.; Yu, M.; Muhuo, Y. Mat. Res. 2014, 17 (5), 1180.

(7) Banerjee, S.; Maji, S. In High Performance Polymers and Engineering Plastics; Mittal, V., Ed.; Hoboken, New Jersey \& Salem, Massachussets, 2011; pp 111-166.

(8) Alger, M. S. M. In Specialty Polymers; Dyson, R. W., Ed.; Springer US: Glasgow and London, 1987; pp 38-64.

(9) Minemawari, H.; Yamada, T.; Matsui, H.; Tsutsumi, J.; Haas, S.; Chiba, R.; Kumai, R.; Hasegawa, T. Nature 2011, 475 (7356), 364.

(10) Yuan, Y.; Giri, G.; Ayzner, A. L.; Zoombelt, A. P.; Mannsfeld, S. C. B.; Chen, J.; Nordlund, D.; Toney, M. F.; Huang, J.; Bao, Z. Nature Communications 2014, 5, 1 .

(11) Takimiya, K.; Osaka, I.; Mori, T.; Nakano, M. Accounts Chem. Res. 2014, 47 (5), 1493.

(12) Takimiya, K.; Shinamura, S.; Osaka, I.; Miyazaki, E. Adv. Mater. 2011, 23 (38), 4347.

(13) Schweicher, G.; Lemaur, V.; Niebel, C.; Ruzié, C.; Diao, Y.; Goto, O.; Lee, W.-Y.; Kim, Y.; Arlin, J.-B.; Karpinska, J.; Kennedy, A. R.; Parkin, S. R.; Olivier, Y.; Mannsfeld, S. C. B.; Cornil, J.; Geerts, Y. H.; Bao, Z. Adv. Mater. 2015, 27 (19), 3066.

(14) Tsutsui, Y.; Schweicher, G.; Chattopadhyay, B.; Sakurai, T.; Arlin, J.-B.; Ruzié, C.; Aliev, A.; Ciesielski, A.; Colella, S.; Kennedy, A. R.; Lemaur, V.; Olivier, Y.; Hadji, R.; Sanguinet, L.; Castet, F.; Osella, S.; Dudenko, D.; Beljonne, D.; Cornil, J.; Samorì, P.; Seki, S.; Geerts, Y. H. Adv. Mater. 2016, 28 (33), 7106.

(15) Illig, S.; Eggeman, A. S.; Troisi, A.; Jiang, L.; Warwick, C.; Nikolka, M.; Schweicher, G.; Yeates, S. G.; Geerts, Y. H.; Anthony, J. E.; Sirringhaus, H. Nature Communications 2016, 7, 1.

(16) Nair, V. S.; Sun, J.; Qi, P.; Yang, S.; Liu, Z.; Zhang, D.; Ajayaghosh, A. Macromolecules 2016, 49 (17), 6334. 
Dischendorfer, O. Monatsh. 1939, 73 (1), 45.

Rosenthal, A.; Zaionchkovsky, A. Can. J. Chem. 1960, 38 (11), 2277.

Coxworth, E. C. M. Can. J. Chem. 1967, 45 (15), 1777.

Mitsui, C.; Tanaka, Y.; Tanaka, S.; Yamagishi, M.; Nakahara, K.; Yano, M.; Sato, H.; Yamano, A.; Matsui, H.; Takeya, J.; Okamoto, T. RSC Adv. 2016, 6, 28966.

Nakahara, K.; Mitsui, C.; Okamoto, T.; Yamagishi, M.; Matsui, H.; Ueno, T.; Tanaka, Y.; Yano, M.; Matsushita, T.; Soeda, J.; Hirose, Y.; Sato, H.; Yamano, A.; Takeya, J. Chem. Commun. 2014, 50 (40), 5342.

Banihasherni, A.; Pourabbas, B. Iran. Polym. J. 1996, 5, 145.

Pourabas, B.; Banihashemi, A. Polym. Int. 2002, 51 (10), 1086.

Banihashemi, A.; Firoozifar, H. Eur. Polym. J. 2003, 39 (2), 281.

Rahmatpour, A. J. Heterocyclic Chem. 2010, 47 (5), 1011.

Rigaku Oxford Diffraction 2015.

Sheldrick, G. M. Acta Cryst. A 2015, 71, 1.

Sheldrick, G. M. Acta Cryst. C 2015, 71, 1.

Furche, F.; Ahlrichs, R.; Hättig, C.; Klopper, W.; Sierka, M.; Weigend, F. WIREs Comput Mol Sci 2013, 4 (2), 91.

Perdew, J. P.; Burke, K.; Ernzerhof, M. Physical Review Letters 1996, 77 (18), 3865.

Weigend, F.; Ahlrichs, R. Phys. Chem. Chem. Phys. 2005, 7 (18), 3297.

Weigend, F. Phys. Chem. Chem. Phys. 2006, 8 (9), 1057.

Trofimov, A. B.; Schirmer, J. J. Phys. B: At. Mol. Opt. Phys. 1995, 28, 2299.

Dreuw, A.; Wormit, M. WIREs Comput Mol Sci 2014, 5 (1), 82.

Adamo, C.; Barone, V. J. Chem. Phys. 1999, 110 (13), 6158.

Hanwell, M. D.; Curtis, D. E.; Lonie, D. C.; Vandermeersch, T.; Zurek, E.; Hutchison, G. R. J Cheminf 2012, 4, 17.

Krebs, F. C.; Faldt, A.; Thorup, N.; Bechgaard, K. CrystEngComm 1999, 1 (6), 21.

Eskildsen, J.; Krebs, F. C.; Faldt, A.; Sommer-Larsen, P.; Bechgaard, K. J. Org. Chem. 2001, 66 (1), 200.

Hasan, M.; Pandey, A. D.; Khose, V. N.; Mirgane, N. A.; Karnik, A. V. Eur. J. Org. Chem. 2015, 2015 (17), 3702.

Nanbu, M.; Momonoi, K.; Oguro, S.; Kawase, Y. B. Chem. Soc. Jpn. 1975, 48 (11), 3421.

Vera, W. J.; Laya, M. S.; Poon, P. S.; Banerjee, A. K.; Cabrera, E. V. ARKIVOC 2013, 396.

Andreetti, G. D.; Bocelli, G.; Sgarabotto, P. Gazz. Chim. Ital. 1974, 104, 1127.

Kawecki, R.; Mazurek, A. P.; Kozerski, L.; Maurin, J. K. Synthesis 1999, 1999 (05), 751.

Goldberg, I.; Shmueli, U. Acta Crystallogr B Struct Crystallogr Cryst Chem 1971, 27 (11), 2164.

Gidron, O.; Diskin-Posner, Y.; Bendikov, M. J. Am. Chem. Soc. 2010, 132 (7), 2148.

Yamazaki, N.; Higashi, F. J. Polym. Sci. B Polym. Lett. Ed. 1974, 12 (4), 185.

Yamazaki, N.; Higashi, F.; Kawabata, J. J. Polym. Sci. Polym. Chem. Ed. 1974, 12 (9), 2149.

Yamazaki, N.; Matsumoto, M.; Higashi, F. J. Polym. Sci. Polym. Chem. Ed. 1975, 13 (6), 1373.

Skrovanek, D. J.; Howe, S. E.; Painter, P. C.; Coleman, M. M. Macromolecules 1985, 18 (9), 1676.

Skrovanek, D. J.; Painter, P. C.; Coleman, M. M. Macromolecules 1986, 19 (3), 699.

Kemmish, D. J. In Practical Guide to High Performance Engineering Plastics; Shawbury, Shrewsbury, Shropshire, United Kingdom, 2011; pp 47-56.

Van Krevelen, D. W. Properties of Polymers, Third Edition. Elsevier Science B. V.: Amsterdam, The Netherlands, 1990.

Klauk, H. Chem. Soc. Rev. 2010, 39 (7), 2643.

Fu, C.; Lin, H.-P.; Macleod, J. M.; Krayev, A.; Rosei, F.; Perepichka, D. F. Chem. Mater. 2016, 28 (3), 951.

Głowacki, E. D.; Romanazzi, G.; Yumusak, C.; Coskun, H.; Monkowius, U.; Voss, G.; Burian, M.; Lechner, R. T.; Demitri, N.; Redhammer, G. J.; Sünger, N.; Suranna, G. P.; Sariciftci, S. Adv. Funct. Mater. 2014, 25 (5), 776.

Głowacki, E. D.; Irimia-Vladu, M.; Kaltenbrunner, M.; Gsiorowski, J.; White, M. S.; Monkowius, U.; Romanazzi, G.; Suranna, G. P.; Mastrorilli, P.; Sekitani, T.; Bauer, S.; Someya, T.; Torsi, L.; Sariciftci, N. S. Adv. Mater. 2012, 25 (11), 1563.

Marty, R.; Szilluweit, R.; Sánchez-Ferrer, A.; Bolisetty, S.; Adamcik, J.; Mezzenga, R.; Spitzner, E.-C.; Feifer, M.; Steinmann, S. N.; Corminboeuf, C.; Frauenrath, H. ACS Nano 2013, 7 (10), 8498.

Wall, B. D.; Diegelmann, S. R.; Zhang, S.; Dawidczyk, T. J.; Wilson, W. L.; Katz, H. E.; Mao, H.-Q.; Tovar, J. D. Adv. Mater. 2011, 23 (43), 5009.

Yagai, S.; Seki, T.; Murayama, H.; Wakikawa, Y.; Ikoma, T.; Kikkawa, Y.; Karatsu, T.; Kitamura, A.; Honsho, Y.; Seki, S. Small 2010, 6 (23), 2731.

Yao, J.; Yu, C.; Liu, Z.; Luo, H.; Yang, Y.; Zhang, G.; Zhang, D. J. Am. Chem. Soc. 2016, 138 (1), 173. 


\section{Table of Contents Figure}

The inclusion of extended $\pi$-conjugated segements into a polyamide provides engineering plastics with additional optoelectronical properties

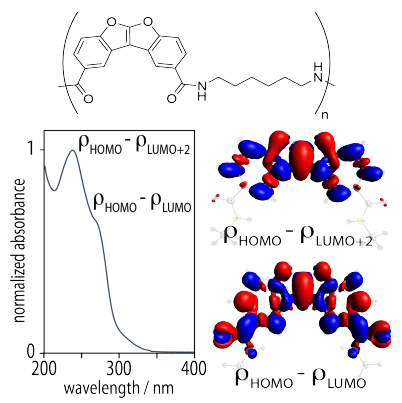

